\title{
openheart Percutaneous coronary intervention causes a rapid but transient mobilisation of $\mathrm{CD} 4^{+} \mathrm{CD} 45^{-}$cells
}

\author{
Gareth J Padfield, ${ }^{1}$ Olga Tura-Ceide,${ }^{2}$ Elizabeth Freyer, ${ }^{1}$ G Robin Barclay, ${ }^{2}$ \\ Marc Turner, ${ }^{2}$ David E Newby, ${ }^{1}$ Nicholas L Mills ${ }^{1}$
}

To cite: Padfield GJ,

Tura-Ceide 0, Freyer E, et al. Percutaneous coronary intervention causes a rapid but transient mobilisation of CD34 ${ }^{+} \mathrm{CD} 45^{-}$cells. Open Heart 2014;1:e000047. doi:10.1136/openhrt-2014000047

Received 27 January 2014 Revised 2 June 2014 Accepted 15 July 2014
CrossMark

\author{
${ }^{1}$ British Heart Foundation \\ Centre for Cardiovascular \\ Science, Edinburgh, UK \\ ${ }^{2}$ Scottish Centre for \\ Regenerative Medicine, \\ University of Edinburgh, \\ Edinburgh, UK
}

Correspondence to Dr Gareth J Padfield; gareth.padfield@nhs.net

\begin{abstract}
Objective: Circulating $\operatorname{CD} 34^{+} \mathrm{CD} 45^{-}$cell concentrations are increased in patients with coronary artery disease, however their pathophysiological significance is unknown. We determined $\mathrm{CD} 34^{+} \mathrm{CD} 45^{-}$ cell concentrations following percutaneous coronary intervention $(\mathrm{PCl})$ in order to explore their role in acute vascular injury.
\end{abstract}

Methods: In a prospective time-course analysis, we quantified using flow cytometry circulating CD $34^{+} \mathrm{CD} 45^{-}$cells, traditional CD34 ${ }^{+} \mathrm{VEGFR}-2^{+}$putative endothelial progenitor cells (EPCs), CD14 ${ }^{+}$VEGFR $^{-}$ $2^{+}{ }^{+}$Tie- $2^{+}$angiogenic monocytes and intercellular adhesion molecule expression (CXCR-4 and CD18) in patients, before and during the first week following diagnostic angiography $(n=13)$ or $\mathrm{PCl}(\mathrm{n}=23)$. Vascular endothelial growth factor-A (VEGF-A) and $C$ reactive protein (CRP) were quantified by ELISA.

Results: Unlike diagnostic angiography, $\mathrm{PCl}$ increased circulating neutrophil and CRP concentrations at 24 and $48 \mathrm{~h}$, respectively ( $p<0.002$ for both). $\mathrm{CD} 34^{+} \mathrm{CD} 45^{-}$cell concentrations were unaffected by angiography $(p>0.4)$, but were transiently increased $6 \mathrm{~h}$ following $\mathrm{PCl}$ (median (IQR) 0.93 (0.43-1.49) vs 1.51 (0.96$2.15) \times 10^{6}$ cells/L; $p=0.01$ ), returning to normal by $24 \mathrm{~h}$. This occurred in the absence of any change in serum VEFG-A concentration, adhesion molecule expression on $\mathrm{CD} 34^{+}$cells, or mobilisation of traditional EPCs or angiogenic monocytes ( $p>0.1$ for all).

Conclusions: $\mathrm{PCl}$ transiently increases circulating $\mathrm{CD}_{4} 4^{+} \mathrm{CD} 45^{-}$cells, without increasing $\mathrm{CD} 34^{+}$adhesion molecule expression or VEGF-A concentrations, suggesting that $\mathrm{CD} 34^{+} \mathrm{CD} 45^{-}$cells may be mobilised from the vessel wall directly as a result of mechanical injury. Traditional putative EPC and angiogenic monocytes are unaffected by PCl, and are unlikely to be important in the acute response to vascular injury.

\section{INTRODUCTION}

Percutaneous coronary intervention (PCI) strips the treated vessel of its endothelium and causes laceration of the underlying intima, initiating platelet aggregation and thrombus formation. ${ }^{1}$ This process triggers an inflammatory cascade that drives vascular smooth muscle proliferation and neo-intimal

\section{KEY MESSAGES}

What is already known about the subject?

- Consistent with preclinical studies, we have previously reported an association between increased $\mathrm{CD} 34^{+} \mathrm{CD} 45^{-}$cell concentrations and coronary artery disease. The clinical significance and the source of this population of cells remain unclear. Conflicting data exist regarding the clinical relevance of traditional CD $34^{+} \mathrm{VEGFR}-2^{+}$ endothelial progenitor cells (EPCs) and their role following acute vascular injury.

What does this study add?

- Consistent with our previous findings, we observe in the present study that $\mathrm{CD} 34^{+} \mathrm{CD} 45^{-}$ are rapidly mobilised following percutaneous coronary intervention (PCl). The functional significance and source of this $\mathrm{CD} 34^{+} \mathrm{CD} 45^{-}$population requires clarification, however it is likely that these cells are derived from the vessel wall. In support of previous work, traditional putative EPCs were unaffected by $\mathrm{PCl}$ and as such it appears unlikely they are important in the acute response to vascular injury.

How might this impact on clinical practice?

- A better understanding of vascular progenitor cells may lead to therapies aimed at enhancing vascular repair in the context of atherosclerotic disease and following angioplasty.

hyperplasia. $^{2}$ The loss of endogenous thrombolytic function and anti-inflammatory signalling by the endothelium potentiates a maladaptive response to vascular injury that can lead to in-stent restenosis or thrombosis. Re-endothelialisation of the denuded arterial segment is therefore of crucial importance in protecting against adverse consequences following PCI. We have previously hypothesised that re-endothelialisation following PCI may be accelerated by circulating angiogenic monocytes and endothelial progenitor cells (EPC). EPCs are naive precursor cells that 
have the capacity to differentiate into mature endothelial cells and contribute to vascular regeneration. ${ }^{3}$

The traditional phenotypic definition of an EPC is based on the co-expression of VEGFR-2, and the stem cell marker CD34, ${ }^{4}$ either alone or in combination with CD133, a haematopoietic cell surface marker expressed only on very naïve cells. ${ }^{6}$ Circulating EPC concentrations are regulated by angiogenic growth factors such as vascular endothelial growth factor and stromal derived factor-1 acting through their cognate receptors, VEGFR-2 and CXCR-4. ${ }^{7-9}$ Peripheral homing and incorporation of EPCs are dependent on the expression of surface adhesion molecules, including $\beta$-integrins such as CD18. ${ }^{10}$ EPCs are mobilised in response to cardiovascular injury such as myocardial infarction, ${ }^{11}$ improve organ perfusion and function in animal models of ischaemia, ${ }^{12}$ and are negatively associated with adverse cardiovascular outcomes. ${ }^{13}{ }^{14}$ Given their putative vasculoprotective role, it is plausible that EPC might be mobilised in order to facilitate vascular repair following injury. However, several investigators have shown previously that acute mobilisation of traditional phenotypic CD34 ${ }^{+}$VEGFR-2 ${ }^{+}$EPCs in response to a discrete vascular injury during PCI does not occur. ${ }^{15}$ Mobilisation of CD $34^{+}$VEGFR-2 ${ }^{+}$cells following PCI may however be delayed, as measurements have not been performed beyond $24 \mathrm{~h}$. In a recent study involving a large cohort of over 200 patients undergoing coronary angiography, we observed that traditional EPC concentrations are unrelated to the severity of coronary atheroma, and are not increased following an acute coronary syndrome (ACS). ${ }^{16}$ This would indicate that traditional EPCs are not clinically relevant to atherosclerosis or acute atherothrombotic events. Indeed EPC, defined in the traditional fashion, are characterised by their capacity to form haematopoietic rather than endothelial colonies in culture, that lack significant proliferative potential or the capacity to incorporate into perfusing vessels in vivo. ${ }^{17}$ In contrast, non-haematopoietic $\mathrm{CD} 34^{+} \mathrm{CD} 45^{-}$cells form endothelial colonies with robust proliferative potential and can incorporate into perfusing vessels. ${ }^{17-19}$ Although not mobilised acutely by an ACS, we found that non-haematopoietic, $\mathrm{CD} 34^{+} \mathrm{CD} 45^{-}$concentrations, are directly associated with atheroma burden and also predict the occurrence of adverse coronary events. ${ }^{16}$ Circulating $\mathrm{CD} 34^{+} \mathrm{CD} 45^{-}$cells therefore serve as a measure of vascular injury, but their origin and pathophysiological significance are unknown. In particular, it is unclear whether or not they are bone marrow-derived cells with regenerative capacity.

Various alternate cell populations have been proposed as having vascular regenerative capacity. In particular, monocytes have received much attention. Monocytes accumulate at sites of new vessel formation and augment the differentiation and proliferation of endothelial cells via the secretion of pro-angiogenic factors. ${ }^{20}{ }^{21}$ Vascular injury associated with PCI mobilises monocyte-derived angiogenic colony forming units (EC-CFU) within $24 \mathrm{~h}$, indicating that this population participates in the acute cellular response to vascular injury. ${ }^{15}$ The specific subpopulations responsible for EC-CFU generation are unknown, however, monocytes expressing the endothelial epitopes vascular endothelial growth factor receptor-2 (VEGFR-2) and Tie-2, accelerate re-endothelialisation and improve left ventricular function following experimental cardiovascular injury, ${ }^{22-24}$ and are mobilised following an ACS. ${ }^{16}$ Their behaviour in response to discrete vascular injury, however, is unknown.

We conducted this study in order to determine the time course of circulating concentrations of a variety of putative angiogenic cell populations over a 1-week period following a discrete vascular injury caused by PCI.

\section{METHODS}

\section{Subjects}

The study was performed with the approval of the local research ethics committee in accordance with the Declaration of Helsinki, and the written informed consent of all volunteers. Patients undergoing elective coronary angiography at Edinburgh Royal Infirmary, Edinburgh, UK, for the investigation of suspected angina (Canadian Cardiovascular Society grade 2 or more) or prior to valve replacement surgery were identified prospectively and invited to take part in the study. Patients with a recent ACS ( $<3$ months), significant comorbid illness, haematological or internal malignancy, hepatic or renal failure or concurrent infection were excluded from the study. Clinical characteristics and medical therapy during admission were documented.

\section{Coronary angiography}

Coronary angiography was performed via the femoral or radial artery using 5-6F arterial catheters and standard angiographic projections. Stenoses affecting a major epicardial artery of $\geq 50 \%$ were defined as significant, and the overall atheroma burden was graded using the Gensini scoring system. ${ }^{25}$ Patients underwent PCI at the discretion of the operator following pretreatment with oral clopidogrel $300 \mathrm{mg}$ and $5000 \mathrm{IU}$ of intravenous unfractionated heparin. Intracoronary stents were implanted following lesion optimisation by balloon predilation and intracoronary glyceryl trinitrate.

\section{Blood sampling and assays}

Prior to coronary angiography, peripheral venous blood anticoagulated with ethylene diamine tetra-acetic acid (Sarstedt-Monovette, Germany) was collected for flow cytometry in all subjects. Whole blood was analysed for the differential leucocyte count using an autoanalyser (Sysmex, UK). Plasma troponin concentrations were measured using the ARCHITECT STAT troponin I assay (Abbott Laboratories, Abbott Park, Illinois, USA). An ELISA was used to quantify serum vascular endothelial growth factor A (VEGF-A) concentration according to the manufacturer's instructions (Invitrogen) ${ }^{26}$ Serum 
high-sensitivity $\mathrm{G}$ reactive protein (CRP) was quantified using an immunoturbidimetric method (Dade-Behring Marburg, Germany). ${ }^{27}$

\section{Flow cytometric identification of EPCs}

EPCs were phenotyped using flow cytometry as previously described. ${ }^{26}$ In brief, cells were stained directly and analysed for phenotypic expression of surface proteins using preconjugated antihuman monoclonal antibodies; anti-CD45-PercP (Becton Dickinson, Oxford, UK); anti-CD34-FITC; anti-VEGFR-2-APC; anti-VEGFR-2-PE;
anti-Tie2-APC; anti-CXCR-4-APC; anti-CD18-PE (R\&D systems, Minneapolis, USA); anti-CD-133-PE (Miltenyi Biotec Ltd, Surrey, UK); and anti-CD14-FITC (Caltag Systems, Buckingham, UK). Flow-cytometric analysis identified leucocytes by their characteristic forward and side scatter profile (figure 1). For each sample, approximately 500000 events were acquired in the leucocyte gate using a FACS-Calibur flow cytometer (Becton Dickinson, UK). Data were analysed using FlowJo (Treestar). For quantification of subpopulations, the proportion of leucocytes bearing each epitope was determined individually
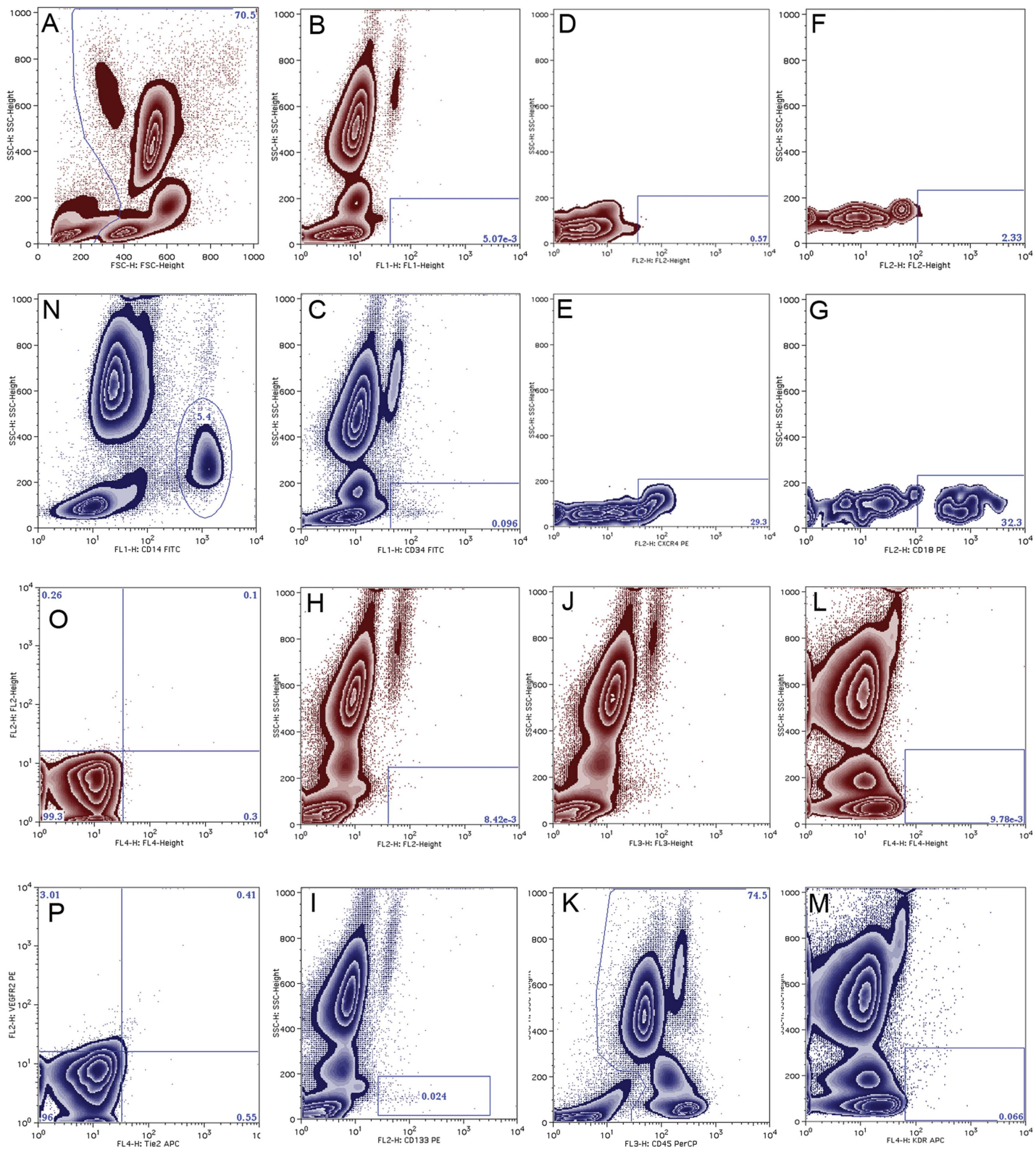

Figure 1 Flow cytometric analysis of putative progenitor cells. Representative dot plots of negative controls and stained samples are shown in red and blue respectively. First, leucocytes were identified on the basis of their characteristic forward and side scatter profile (A). CD34-FITC (B and C) expression and the proportion of CD34 ${ }^{+}$events expressing CD18 (D and E) and CXCR-4 ( $F$ and G) were determined. Similarly CD133-PE ${ }^{+}\left(\mathrm{H}\right.$ and I), CD45-Perc $\mathrm{P}^{+}$( $\mathrm{J}$ and K), and VEGFR-2-APC ${ }^{+}(\mathrm{L}$ and M) events were identified. Co-expression of surface markers was determined using Boolean principles. In separate analyses CD14-FITC ${ }^{+}$events were identified (N), and those expressing Tie-2-APC and or VEGFR-2-PE were determined using quadrant analysis $(\mathrm{O}$ and $\mathrm{P})$. Gates were set on single or unstained negative controls where appropriate. 
using side scatter profile against the appropriate fluorescence channel, and permutations of co-expression were determined automatically using Boolean principles. Unstained samples served as negative controls (figure 1). Absolute cell concentrations per millilitre of blood were calculated by equating the total number of events in the leucocyte gate to the total leucocyte count.

\section{Data analysis and statistics}

Continuous variables are reported as the mean $\pm \mathrm{SD}$ or median and inter-quartile range where appropriate. Statistical analyses were performed with SPSS V.17 (SPSS Inc, Chicago, USA). The Shapiro-Wilk test was used to test for normality of distribution. Analyses were performed using parametric or non-parametric analysis of variance (ANOVA), where appropriate. The two-tailed Student t test, Mann-Whitney tests and Pearson's $\chi^{2}$ tests for between and within group comparisons were performed where appropriate. Statistical significance was taken at a two-sided $\mathrm{p}$ value of 0.05 . At a significance level of $5 \%$ and based on power calculations derived from previous studies, a sample size of $n=20$ will give
$80 \%$ power of detecting a twofold increase in traditional phenotypic EPC (CD34 ${ }^{+} \mathrm{VEGFR}^{2}{ }^{+}$cells).

\section{RESULTS \\ Subjects and procedures}

Thirteen patients underwent diagnostic coronary angiography alone and 23 underwent PCI using intracoronary stents. Patients were well matched in terms of age and sex and with respect to their cardiovascular risk profile and baseline medications (table 1). A diagnosis of hypertension was more frequently present in patients undergoing PCI compared to diagnostic coronary angiography alone ( $46 \%$ vs $83 \%$; $p=0.02$ ). Patients undergoing diagnostic coronary angiography alone were more likely to have left main stem or three-vessel disease $(\mathrm{p}=0.001)$, although Gensini scores were similar (26 (16-80) vs $34(26-79)$ units; $\mathrm{p}>0.70)$. Patients undergoing PCI required a longer total procedure time compared to diagnostic angiography alone $(36 \pm 2.2$ vs $16 \pm 1.6 \mathrm{~min} ; \mathrm{p}<0.001)$. Patients received a median of 1 (1-2) stent with a median total balloon inflation time of $44(30-54)$ seconds. Drug eluting stents were used in $57 \%$ of patients (table 2 ). No

Table 1 Demographic, clinical characteristics and medical therapy of the study population

\begin{tabular}{|c|c|c|c|}
\hline & Angiography $(n=13)$ & $\mathrm{PCl}(\mathrm{n}=23)$ & p Value \\
\hline \multicolumn{4}{|l|}{ Demographics } \\
\hline Age, years & $63 \pm 2.7$ & $61 \pm 2.3$ & 0.51 \\
\hline Male gender, $\mathrm{n}(\%)$ & $10(77)$ & $19(83)$ & 0.68 \\
\hline Body mass index, $\mathrm{kg} / \mathrm{m}^{2}$ & $27.5 \pm 1.8$ & $28.9 \pm 0.9$ & 0.51 \\
\hline \multicolumn{4}{|l|}{ Clinical characteristics } \\
\hline \multicolumn{4}{|l|}{ Smoking status, n (\%) } \\
\hline Current smoker & $4(31)$ & $2(9)$ & 0.11 \\
\hline Ex smoker & $6(46)$ & $11(48)$ & 0.71 \\
\hline Non smoker & $3(23)$ & $10(44)$ & 0.22 \\
\hline Hypertensive, n (\%) & $6(46)$ & $19(83)$ & 0.02 \\
\hline Diabetic, n (\%) & $2(15)$ & $3(13)$ & 0.85 \\
\hline Hyperlipidaemia, n (\%) & $8(62)$ & $17(74)$ & 0.32 \\
\hline Family history of CAD, $\mathrm{n}(\%)$ & $5(39)$ & $16(70)$ & 0.07 \\
\hline Previous MI, n (\%) & $5(39)$ & $13(57)$ & 0.30 \\
\hline CABG, n (\%) & $1(8)$ & $2(9)$ & 0.92 \\
\hline $\mathrm{PCl}, \mathrm{n}(\%)$ & $2(15)$ & $10(44)$ & 0.09 \\
\hline PVD, n (\%) & $2(15)$ & $3(13)$ & 0.85 \\
\hline LVSD, n (\%) & $3(23)$ & $6(26)$ & 0.84 \\
\hline Stroke, n (\%) & $1(8)$ & $1(4)$ & 0.67 \\
\hline Creatinine, mg/dL & $103 \pm 4$ & $98 \pm 3$ & 0.34 \\
\hline Cholesterol, mg/dL & $4.3 \pm 0.3$ & $4.4 \pm 0.2$ & 0.95 \\
\hline \multicolumn{4}{|l|}{ Medical therapy } \\
\hline Aspirin, n (\%) & $9(77)$ & $23(100)$ & 0.05 \\
\hline Clopidogrel, n (\%) & $4(31)$ & $18(78)$ & 0.01 \\
\hline$\beta$-blocker, $n(\%)$ & $7(54)$ & $17(74)$ & 0.22 \\
\hline Statin, n (\%) & $10(77)$ & $22(96)$ & 0.09 \\
\hline ACE inhibitor, $n(\%)$ & $4(31)$ & $14(61)$ & 0.08 \\
\hline ARB, n (\%) & $1(8)$ & $1(4)$ & 0.67 \\
\hline
\end{tabular}

Continuous variables are expressed as the mean \pm SE or median (IQR) with statistical comparisons between patients with ACS and suspected stable angina performed using the Student $t$ test or Mann-Whitney, where appropriate. Categorical variables are expressed as the absolute number of cases and the group proportion (\%) with statistical comparisons performed using a $\chi^{2}$ test.

ARB, angiotensin receptor blocker; CABG, coronary artery bypass; CAD, coronary artery disease; LVSD, left ventricular systolic dysfunction; $\mathrm{MI}$, myocardial infarction; $\mathrm{PCI}$, percutaneous coronary intervention; PVD, peripheral vascular disease. 
Table 2 Procedural characteristics of the study population

\begin{tabular}{|c|c|c|c|}
\hline & $\begin{array}{l}\text { Angiography } \\
(n=13)\end{array}$ & $\begin{array}{l}\mathrm{PCl} \\
(n=23)\end{array}$ & $\begin{array}{l}\mathbf{p} \\
\text { Value }\end{array}$ \\
\hline Radial access, n (\%) & $9(69)$ & $18(78)$ & 0.55 \\
\hline \multicolumn{4}{|c|}{ Coronary disease severity } \\
\hline $\begin{array}{l}\text { Normal/minor } \\
\text { disease, n (\%) }\end{array}$ & $2(15)$ & $1(5)$ & 0.27 \\
\hline 1 vessel, $n(\%)$ & $2(15)$ & $10(46)$ & 0.09 \\
\hline 2 vessel, $n(\%)$ & $2(15)$ & $6(27)$ & 0.46 \\
\hline 3 vessel, n (\%) & $7(54)$ & $5(23)$ & 0.05 \\
\hline $\begin{array}{l}3 \text { vessel or left } \\
\text { main stem, } n(\%)\end{array}$ & $9(69)$ & $5(23)$ & 0.01 \\
\hline $\begin{array}{l}\text { Gensini score, } \\
\text { units }\end{array}$ & $34(26-79)$ & $26(16-80)$ & 0.70 \\
\hline \multicolumn{4}{|l|}{ Target vessel, n (\%) } \\
\hline LAD & - & $11(48)$ & - \\
\hline LCx & - & $10(44)$ & - \\
\hline RCA & - & $5(22)$ & - \\
\hline SVG & - & $2(9)$ & - \\
\hline Multivessel & - & $7(30)$ & - \\
\hline $\begin{array}{l}\text { Balloon inflation } \\
\text { time, s }\end{array}$ & - & $44(30-54)$ & - \\
\hline Number of stents & - & $1(1-2)$ & - \\
\hline Drug eluting stents & - & $13(57)$ & - \\
\hline Stent length, mm & - & $25.3 \pm 3.2$ & - \\
\hline Stent diameter, $\mathrm{mm}$ & - & $3.1 \pm 0.1$ & - \\
\hline Predilation, n (\%) & - & $18(78)$ & - \\
\hline Postdilation, n (\%) & - & $4(17)$ & - \\
\hline Case time, $\min$ & $16 \pm 1.6$ & $36 \pm 2.2$ & $<0.001$ \\
\hline
\end{tabular}

Continuous variables are expressed as the mean \pm SE or median and IQR with statistical comparisons between patients with ACS and suspected stable angina performed using the Student $t$ test or Mann-Whitney, where appropriate. Categorical variables are expressed as the absolute number of cases and the group proportion (\%) with statistical comparisons performed using a $\chi^{2}$ test. Statistical comparisons were performed using the Student $\mathrm{t}$ test, Mann-Whitney test or $\chi^{2}$ analysis where appropriate. $L A D$, left anterior descending; LCx, left circumflex; $P C I$, percutaneous coronary intervention; RCA, right coronary artery; SVG, saphenous vein graft.

significant complications arose during the course of the study and all patients were discharged within $24 \mathrm{~h}$ of the procedure.

\section{Measures of inflammation and myocyte necrosis}

All parameters were similar in both groups at baseline ( $p>0.05$ for all; table 3 ). The median troponin concentration at $24 \mathrm{~h}$ was undetectable in both groups $(\mathrm{p}=0.13)$. Following PCI, the leucocyte count was increased ( $p=0.04$ for ANOVA of repeated measures), peaking at $24 \mathrm{~h}\left(7.21 \pm 0.28\right.$ vs $6.24 \pm 0.20 \times 10^{6}$ cells $/ \mathrm{L}$; $\mathrm{p}=0.002)$. Serum CRP also increased following PCI ( $\mathrm{p}=0.002$ for ANOVA of repeated measures), peaking at $48 \mathrm{~h} \quad(3.95 \quad(1.26-8.26) \quad$ vs $1.02 \quad(0.64-2.33) \mathrm{mg} / \mathrm{L}$; $\mathrm{p}=0.001)$. Serum VEGF-A concentrations were unchanged following PCI $(p=0.16$ for ANOVA of repeated measures). Diagnostic coronary angiography alone had no effect on the total leucocyte count, CRP or serum VEGF-A concentration throughout the study period ( $p>0.5$ for ANOVA of repeated measures for all).

\section{Progenitor cell populations}

All cell concentrations were similar in both groups at baseline ( $p>0.2$ for all; table 4 ). Following PCI circulating $\mathrm{CD} 34^{+} \mathrm{CD} 45^{-}$cell concentrations were increased ( $p=0.0001$, for one-way ANOVA of repeated measures), peaking at $6 \mathrm{~h}$ before returning to baseline concentrations at $24 \mathrm{~h} \quad(1.51 \quad(0.96-2.15) \quad \mathrm{v} \quad 0.93 \quad(0.43-$ $1.49) \times 10^{6}$ cells $/ \mathrm{L} ; \mathrm{p}=0.01$; table 4 and figure 2$)$. The $\mathrm{CD} 34^{+} \mathrm{CD} 45^{-}$concentration was unaffected by diagnostic coronary angiography alone $(\mathrm{p}=0.43$ for ANOVA of repeated measures; table 4 and figure 2). Traditional EPC phenotypes expressing CD34 $4^{+}$EGFR-2 $2^{+}$and those

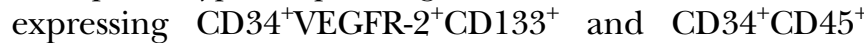
were unaffected in both groups $(\mathrm{p}>0.2$ for all; table 4$)$. CXCR-4 and CD18 expression on CD $34^{+}$cells was $47 \pm 7 \%$ and $36 \pm 5 \%$, respectively, at baseline and were unchanged throughout the study period in both groups $(p>0.2$ for all; data not shown). The total CD14 count was not affected by either procedure ( $>0.5$ for both). Angiogenic monocytes expressing Tie-2 and VEGFR-2 comprised $0.72 \%(0.28-2.65)$ of circulating $\mathrm{CD} 14^{+}$cells and circulating concentrations were unchanged throughout the study in both groups ( $\mathrm{p}>0.2$ for all; table 4$)$.

\section{DISCUSSION}

We have examined the behaviour of a variety of circulating angiogenic cells in response to a discrete vascular injury caused by PCI. We observed a rapid but transient mobilisation of $\mathrm{CD}^{+} 4^{+} \mathrm{CD} 45^{-}$cells into the peripheral circulation following PCI, with circulating concentrations returning to baseline by $24 \mathrm{~h}$. The systemic inflammatory response caused by PCI however, was relatively prolonged and continued to increase for at least $48 \mathrm{~h}$. $\mathrm{CD} 34^{+} \mathrm{CD} 45^{-}$cells were mobilised without a detectable change in $\mathrm{CD}^{+} 4^{+}$surface adhesion molecules or serum VEGF-A concentration. Taken together, these observations would suggest that mobilisation of $\mathrm{CD} 34^{+} \mathrm{CD} 45^{-}$ cells following PCI is not mediated by a circulating cytokine or growth factor acting on the bone marrow. Given the close association between $\mathrm{CD} 34^{+} \mathrm{CD} 45^{-}$and atheroma burden that we have previously observed, ${ }^{16}$ it is plausible that mechanical injury causes $\mathrm{CD} 34^{+} \mathrm{CD} 45^{-}$ cells to be released from the coronary artery directly. Traditional phenotypic EPC populations $\left(\right.$ CD $34^{+}{ }^{+}$EGFR-2 ${ }^{+}$and CD $34^{+}$VEGFR-2 ${ }^{+} \mathrm{CD} 133^{+}$), and haematopoietic $\mathrm{CD} 45^{+}$subpopulations including angiogenic monocytes were both unaffected by discrete vascular injury up to 1 week following PCI. This would suggest that these populations are not mobilised in acute response to vascular injury and are unlikely to play a direct role in vascular repair; however, it remains possible that local cytokine production might increase adhesion of circulating proangiogenic monocytes or $\mathrm{CD} 34^{+}$ cells to increase incorporation of these cell types to sites 


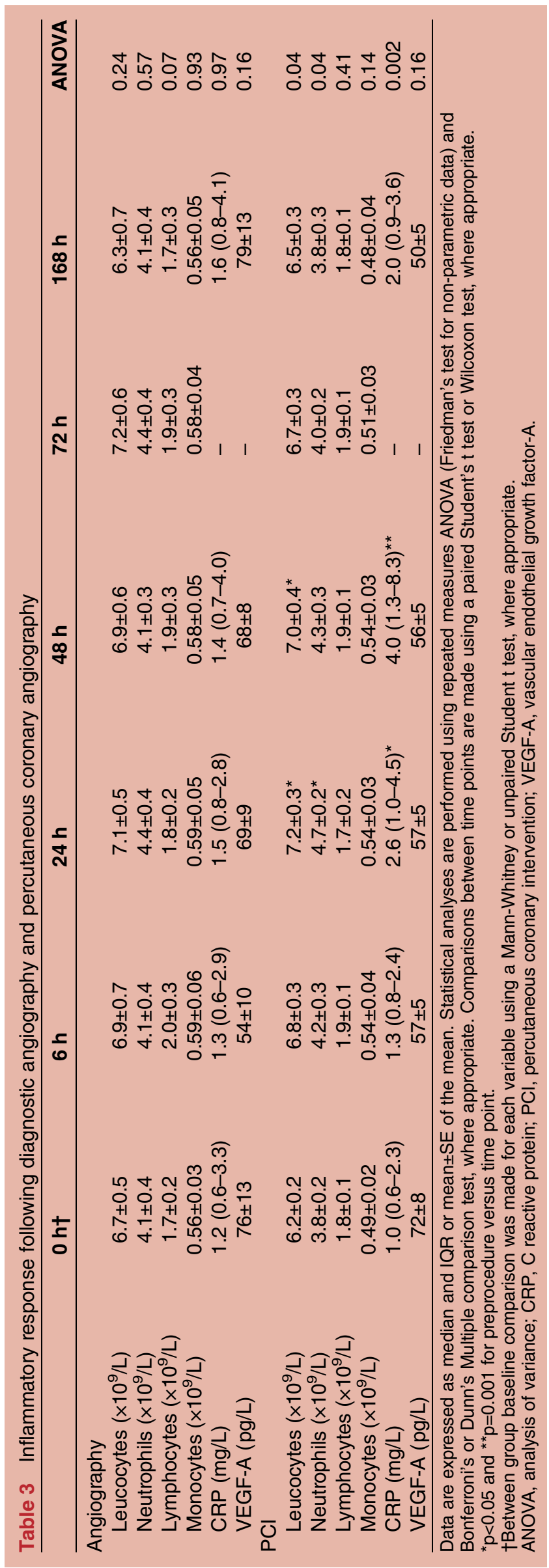

of vascular injury. Two small clinical studies have demonstrated a fall in CD34 ${ }^{+}$VEGFR-2 ${ }^{+}$cells within the first few hours of coronary angioplasty. Neither of these studies used a control group, and interpretation is therefore limited, but it is likely that this 'dip' in CD34 ${ }^{+}$cell concentration is explained by the diurnal variation that is recognised to affect these populations, ${ }^{26}$ rather than incorporation to sites of vascular denudation. Previous studies have not specifically examined the behaviour of $\mathrm{CD} 34^{+} \mathrm{CD} 45^{-}$cells following PCI. Pelliccia $e t a t^{28}$ found that higher concentrations of circulating CD $34^{+}$VEGFR-2 $2^{+} \mathrm{CD} 45^{-}$and $\mathrm{CD} 133^{+}{ }^{+}$VEGFR-2 ${ }^{+} \mathrm{CD} 45^{-}$ cells prior to revascularisation identified patients more likely to develop restenosis. Similarly, a direct relationship exists between coronary atheroma burden and both $\mathrm{CD} 34^{+} \mathrm{CD} 45^{-}$cells $^{16}$ and $\mathrm{CD} 34^{+} \mathrm{CD} 45^{-}$cell-derived late outgrowth colonies. ${ }^{29} \mathrm{CD} 34^{+} \mathrm{CD} 45^{-}$cells are therefore a measure of vascular injury; however, whether or not they are derived from the bone marrow or possess reparatory function remains unclear. Mature endothelial cells also express $\mathrm{CD}_{3} 4^{+30}$ and are $\mathrm{CD} 45^{-}$, and circulating $\mathrm{CD} 34^{+} \mathrm{CD} 45^{-}$cells may therefore simply reflect shedding of vascular detritus to the peripheral circulation as a consequence of cell turnover in atherosclerotic arteries. The early and transient appearance of $\mathrm{CD} 34^{+} \mathrm{CD} 45^{-}$ cells in the circulation following vascular perturbation observed in the current study is consistent with this hypothesis. Furthermore, despite mobilisation of $\mathrm{CD} 34^{+} \mathrm{CD} 45^{-}$cells, neither plasma VEGF concentration nor the expression of the surface receptors, CXCR-4 or CD18 on circulating CD $34^{+}$cells were affected by PCI. It is possible that we have observed progenitor cell mobilisation from either the marrow or a marginated, vascular resident population and have failed to detect the circulating factors responsible for their release. Stem cell mobilisation occurs via activation of the phosphatidylinositol 3-kinase/Akt/endothelial nitric oxide synthase (PI3K/Akt/eNOS) pathway via angiogenic factors such as VEGF, through the stimulation of nitric oxide synthesis by bone marrow stromal cells. ${ }^{8}$ Increased nitric oxide bioavailability leads to cleavage of intracellular adhesions between stem cells and stromal cells of the bone marrow, ${ }^{31}$ allowing them to mobilise to the peripheral circulation in response to a stromal cell-derived factor-1 gradient generated by bone marrow stromal cells acting through the CXCR-4 receptor. ${ }^{7}$ Cell surface adhesion molecules such as CD18 mediate EPC homing and cells adhesion and are required for incorporation of EPCs into the vasculature. ${ }^{10}$ Although we have not performed a comprehensive evaluation of the factors involved in the mobilisation of stem cells from the bone marrow, the absence of any change in VEGF concentration or CD18 and CXCR-4 expression further supports the hypothesis that $\mathrm{CD} 34^{+} \mathrm{CD} 45^{-}$cells were not mobilised from the bone marrow, but released directly from the injured coronary artery. ${ }^{16} 32$

While we did not observe an increase in $\mathrm{CD} 34^{+} \mathrm{CD} 45^{-}$ cells in the present study, this has been described 
Table 4 Cell frequencies following diagnostic angiography and percutaneous coronary intervention

\begin{tabular}{|c|c|c|c|c|c|c|c|}
\hline & $\mathbf{O} \mathbf{h}^{*}$ & $6 \mathrm{~h}$ & $24 \mathrm{~h}$ & $48 \mathrm{~h}$ & $72 \mathrm{~h}$ & $168 \mathrm{~h}$ & ANOVA \\
\hline \multicolumn{8}{|l|}{ Angiography } \\
\hline $\mathrm{CD} 34^{+}$ & $2.45(1.54-3.21)$ & $2.17(1.59-2.94)$ & $1.63(1.37-2.28)$ & $1.74(1.31-2.75)$ & $2.17(1.35-3.13)$ & $1.88(1.66-2.79)$ & 0.14 \\
\hline $\mathrm{CD} 4^{+}$VEGFR-2 ${ }^{+}$ & $0.27(0.09-0.71)$ & $0.36(0.08-1.50)$ & $0.13(0.03-0.41)$ & $0.21(0.09-0.48)$ & $0.06(0.02-0.40)$ & $0.13(0.07-0.87)$ & 0.22 \\
\hline $\mathrm{CD} 4^{+}$VEGFR-2 ${ }^{+} \mathrm{CD} 133^{+}$ & $0.04(0.01-0.55)$ & $0.10(0.03-0.44)$ & $0.10(0.0-0.36)$ & $0.05(0.01-0.19)$ & $0.03(0.0-0.49)$ & $0.03(0.0-0.24)$ & 0.44 \\
\hline $\mathrm{CD}_{3} 4^{+} \mathrm{CD} 45^{+}$ & $1.77(0.90-2.48)$ & $1.11(0.94-1.87)$ & $1.31(0.97-1.96)$ & $1.36(1.08-1.69)$ & $1.46(0.86-1.96)$ & $1.36(0.81-1.67)$ & 0.73 \\
\hline $\mathrm{CD} 34^{+} \mathrm{CD} 45^{-}$ & $0.71(0.31-1.20)$ & $0.60(0.31-1.70)$ & $0.39(0.27-0.82)$ & $0.41(0.26-0.67)$ & $0.52(0.21-1.4)$ & $0.61(0.21-1.1)$ & 0.43 \\
\hline $\mathrm{CD} 34^{+} \mathrm{CD} 45^{-}$VEGFR-2 ${ }^{+}$ & $0.06(0.01-0.31)$ & $0.08(0.02-0.31)$ & $0.02(0.002-0.17)$ & $0.06(0.0-0.13)$ & $0.02(0.0-0.29)$ & $0.05(0.01-0.11)$ & 0.33 \\
\hline CD14 ${ }^{+}$Tie $2^{+}$VEGFR $-2^{+} \dagger$ & $3.0(1.8-11.1)$ & $2.8(1.2-14.3)$ & $2.0(1.3-10.8)$ & $2.5(0.70-6.37)$ & $3.2(2.1-12.6)$ & $2.7(0.97-8.61)$ & 0.39 \\
\hline \multicolumn{8}{|l|}{$\mathrm{PCl}$} \\
\hline $\mathrm{CD}^{+} 4^{+}$ & $2.58(1.70-3.36)$ & $2.94(2.07-4.05)$ & $2.36(1.74-3.52)$ & $2.42(1.75-3.29)$ & $2.20(1.60-2.64)$ & 2.49 (1.36-3.25) & 0.08 \\
\hline $\mathrm{CD} 4^{+}$VEGFR-2 ${ }^{+}$ & $0.13(0.02-0.52)$ & $0.18(0.05-0.85)$ & $0.17(0.03-0.47)$ & $0.22(0.02-0.56)$ & $0.12(0.05-0.41)$ & $0.11(0.03-0.38)$ & 0.3 \\
\hline $\mathrm{CD} 4^{+}$VEGFR $-2^{+} \mathrm{CD} 133^{+}$ & $0.05(0.0-0.92)$ & $0.14(0.0-1.3)$ & $0.04(0.0-0.77)$ & $0.08(0.0-0.75)$ & $0.03(0.0-0.74)$ & $0.04(0.0-0.72)$ & 0.27 \\
\hline $\mathrm{CD}_{3} 4^{+} \mathrm{CD} 45^{+}$ & $1.41(0.84-2.14)$ & $1.69(0.97-2.34)$ & $1.79(1.12-2.69)$ & $1.64(1.28-2.11)$ & $1.72(0.96-2.07)$ & $1.63(0.96-2.34)$ & 0.6 \\
\hline $\mathrm{CD} 34^{+} \mathrm{CD} 45^{-}$ & $0.93(0.43-1.49)$ & $1.51(0.96-2.15) \ddagger$ & $0.71(0.40-0.98)$ & $0.70(0.46-1.14)$ & $0.52(0.21-0.73)$ & $0.76(0.36-1.05)$ & $<0.0001$ \\
\hline $\mathrm{CD} 34^{+} \mathrm{CD} 45^{-}$VEGFR $-2^{+}$ & $0.09(0.0-0.32)$ & $0.17(0.02-0.52)$ & $0.09(0.01-0.37)$ & $0.06(0.0-0.36)$ & $0.05(0.0-0.19)$ & $0.04(0.02-0.16)$ & 0.1 \\
\hline 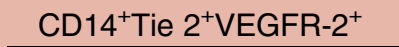 & $3.1(0.98-7.1)$ & $4.3(2.4-13)$ & $4.1(1.8-11)$ & $3.1(0.30-13)$ & $3.1(0.55-6.1)$ & $2.1(1.1-9.3)$ & 0.68 \\
\hline
\end{tabular}

Concentrations are the median and IQR $\times 10^{6} / \mathrm{L}$ of blood. Statistical analyses are performed using repeated measures ANOVA (Friedman's test) with Dunn's Multiple comparison post test.

Comparisons between time points are made using a Wilcoxon test.

${ }^{*}$ Between group comparisons at baseline were made for each variable using a Mann-Whitney test.

$+n=10$.

$\neq \mathrm{f}=0.01$ for baseline compared to time point.

ANOVA, analysis of variance; CD, cluster of differentiation; CRP, C reactive protein; PCI, percutaneous coronary intervention; VEGFR-2, vascular endothelial growth factor receptor-2. 


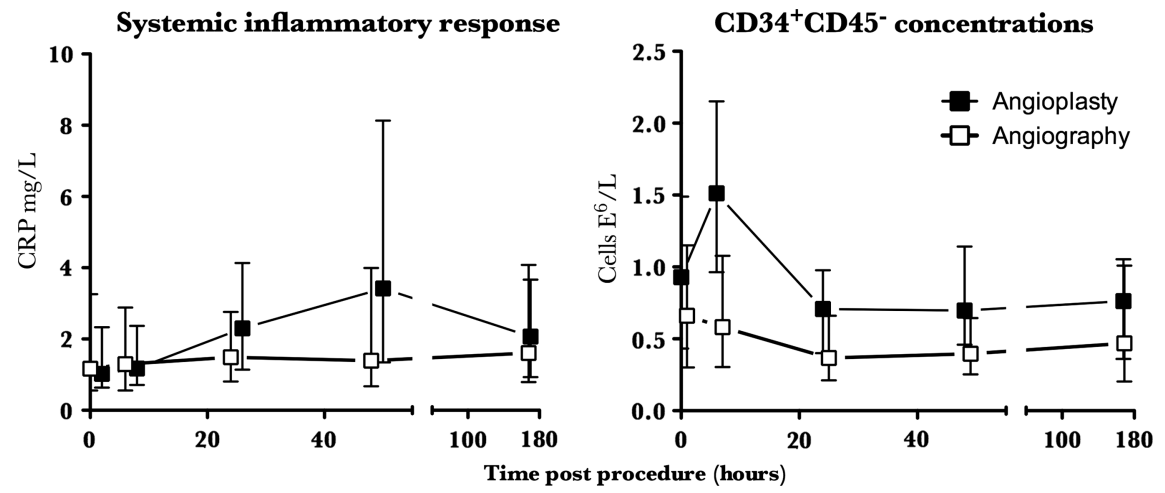

Figure 2 Inflammatory response and $\mathrm{CD} 34^{+} \mathrm{CD} 45^{-}$cell release following percutaneous coronary intervention ( $\left.\mathrm{PCl}\right)$. $\mathrm{PCl}$ rapidly but transiently mobilised $\mathrm{CD} 34^{+} \mathrm{CD} 45^{-}$cells into the peripheral circulation, peaking at $6 \mathrm{~h} ; \mathrm{p}=0.01$. Circulating concentrations had fallen back to baseline by $24 \mathrm{~h}$. In contrast, the systemic inflammatory response caused by PCl was relatively prolonged, with CRP concentrations continuing to increase for at least $48 \mathrm{~h} ; \mathrm{p}=0.001$. Diagnostic coronary angiography alone did not cause an inflammatory response or effect the $\mathrm{CD} 34^{+} \mathrm{CD} 45^{-}$concentration; $\mathrm{p}>0.5$ for all. Data are median and IQR.

following PCI, previously. However, these studies did not evaluate vascular injury in isolation and included patients with significant myocardial necrosis following acute myocardial infarction. ${ }^{33} 34$ Peak mobilisation varied from $24 \mathrm{~h}$ to a week, and was proportional to the degree of systemic inflammation with $\mathrm{CD} 34^{+} \mathrm{CD} 45^{-}$concentrations predicting future development of in-stent restenosis. Whether $\mathrm{CD} 34^{+} \mathrm{CD} 45^{-}$cells contribute directly to the development of restenosis is unknown, although it is interesting to note that the use of drug-eluting stents was associated with less inflammation and $\mathrm{CD}^{+} 4^{+} \mathrm{CD} 45^{-}$mobilisation. This suggests drug-eluting stents may in part suppress restenosis by attenuating inflammatory typo (signaling) to the bone marrow by suppressing local vascular inflammation. $\mathrm{CD} 34^{+} \mathrm{CD} 45^{-}$cells have the capacity to adopt smooth muscle cell characteristics in vitro and may therefore potentiate the development of in-stent restenosis by acting as circulating smooth muscle progenitor cells. ${ }^{35}$ Putative smooth muscle progenitor cells have been reported to express both CD34 and VEGFR-2, ${ }^{36}$ and both CD34 and CD133 are expressed at higher concentrations in the neo-intima of restenotic lesions compared with de novo lesions. ${ }^{37}$ Inoue $e t a l^{33}$ demonstrated that circulating mononuclear cells of patients with in-stent restenosis exhibit a propensity to develop a smooth muscle phenotype over that of an endothelial phenotype compared with those without. Therefore, plasticity of circulating $\mathrm{CD}^{+} 4^{+}$cells may lead to acceleration of neo-intimal hyperplasia if a pro-inflammatory microenvironment in a particular patient dictates such a response.

Monocytes will express a variety of endothelial characteristics in-vitro under appropriate angiogenic stimulation. ${ }^{20} 38{ }^{39}$ Monocyte chemoattractant protein-1 (MCP-1) is released by endothelial cells in response to shear stress and tissue ischaemia, ${ }^{40}$ causing monocytes to accumulate at sites of new vessel formation, adhere to injured endothelium, accelerate re-endothelialisation and improve endothelial vasomotor function. ${ }^{22} 23$ However, the remarkable plasticity of monocytes may result in a diverse response to vascular injury depending on the local microenvironment. For instance, there is a strong correlation between circulating monocyte concentration and the development of in-stent restenosis, ${ }^{41}$ and MCP-1 is significantly elevated in both plasma ${ }^{42}$ and coronary atherectomy specimens of patients who develop in-stent restenosis following PCI. ${ }^{43}$ Furthermore, treatment with anti-MCP-1 monoclonal antibodies following balloon angioplasty in rats inhibits neo-intimal hyperplasia. ${ }^{44}$ The role of monocytes following vascular injury is therefore diverse and again probably depends on the local microenvironment. PCI mobilises EC-CFU within $24 \mathrm{~h}$ although whether specific subpopulations participate in the acute cellular response to vascular injury is unknown. ${ }^{15}$ We recently observed that monocytes expressing Tie-2 and VEGFR-2 are mobilised acutely following an ACS; however, this appeared to be a concequence of myocyte necrosis rather than the presence of atheroma burden or the presence of an ACS, per se. ${ }^{16}$ In the present study, CD14 ${ }^{+}$Tie- $2^{+}$VEGFR-2 ${ }^{+}$cells were not mobilised following PCI, suggesting that mobilisation of this monocytic subpopulation occurs in response to more extensive myocardial injury rather than discrete vascular injury.

\section{STUDY LIMITATIONS}

Although we hypothesise that $\mathrm{CD} 34^{+} \mathrm{CD} 45^{-}$cells have been liberated directly from the coronary artery, we have not proven this definitively and further confirmatory studies are required. Patients undergoing PCI were more frequently hypertensive. Hypertension has been linked to impaired mobilisation of 'EPC' and related cell populations, and this may therefore be relevant to our results. ${ }^{45}$ If PCI-mediated vascular injury does mobilise traditional EPC, this effect might be muted in a group of hypertensive patients, potentially leading to a type 2 error. 
However, previous investigators have demonstrated the absence of mobilisation of traditional EPC in a group of largely non-hypertensive patients. ${ }^{46}$ Patients undergoing PCI were all administered heparin, which has been shown to increase circulating CD $34^{+}$cell concentrations, possibly through disruption of SDF/CXCR-4 interaction. ${ }^{47}$ Heparin may have led to $\mathrm{CD} 34^{+} \mathrm{CD} 45^{-}$mobilisation; however, if this were the case one would expect the $\mathrm{CD} 45^{+}$fraction to be similarly increased.

\section{CONCLUSIONS}

Discrete vascular injury associated with PCI causes a rapid but transient release of $\mathrm{CD} 34^{+} \mathrm{CD} 45^{-}$cells into the peripheral circulation in the absence of a concurrent increase in $\mathrm{CD}^{+} 4^{+}$adhesion molecule expression or VEGF-A secretion. Confirmatory studies are required to determine whether $\mathrm{CD} 34^{+} \mathrm{CD} 45^{-}$cells released into the circulation following PCI arise directly from the vessel wall through mechanical injury, or are progenitors with reparatory capacity mobilised from a stem cell niche. Traditional EPC and VEGFR-2 ${ }^{+} \mathrm{Tie}^{-2^{+}}$monocytes are unaffected by PCI, and are unlikely to be important in the acute response to vascular injury.

Contributors All authors contributed significantly to the work. GJP and NLM devised and conducted the research and wrote the manuscript along with DEN. EF assisted with data acquisition and analyses. OT-C, GRB and MT assisted with data analysis and manuscript preparation. GJP and NLM take overall responsibility for the manuscript.

Funding The research was supported by a BHF Project Grant (PG/07/017/ 22405). The Wellcome Trust Clinical Research Facility is supported by NHS Research Scotland (NRS) through NHS Lothian.

Competing interests A British Heart Foundation (BHF) Scholarship (SS/CH/ 92010) and Intermediate Clinical Research Fellowship (FS/10/024) supported GJP and NLM, respectively. DEN is supported by the British Heart Foundation $(\mathrm{CH} / 09 / 002)$

Ethics approval Lothian Research Ethics Committee.

Provenance and peer review Not commissioned; externally peer reviewed.

Data sharing statement Technical appendix, statistical code and dataset are available on request. Explicit informed consent for data sharing was not given but the risk of identification is low.

Open Access This is an Open Access article distributed in accordance with the Creative Commons Attribution Non Commercial (CC BY-NC 3.0) license, which permits others to distribute, remix, adapt, build upon this work noncommercially, and license their derivative works on different terms, provided the original work is properly cited and the use is non-commercial. See: http:// creativecommons.org/licenses/by-nc/3.0/

\section{REFERENCES}

1. Mak KH, Belli G, Ellis SG, et al. Subacute stent thrombosis: evolving issues and current concepts. J Am Coll Cardiol 1996;27:494-503.

2. Farb A, Sangiorgi G, Carter AJ, et al. Pathology of acute and chronic coronary stenting in humans. Circulation 1999;99:44-52.

3. Padfield GJ, Newby DE, Mills NL. Understanding the role of endothelial progenitor cells in percutaneous coronary intervention. J Am Coll Cardiol 2010;55:1553-65.

4. Cheng J, Baumhueter S, Cacalano G, et al. Hematopoietic defects in mice lacking the sialomucin CD34. Blood 1996;87:479-90.

5. Shalaby F, Rossant J, Yamaguchi TP, et al. Failure of blood-island formation and vasculogenesis in Flk-1-deficient mice. Nature 1995;376:62-6.
6. Yang $\mathrm{C}$, Zhang ZH, Li ZJ, et al. Enhancement of neovascularization with cord blood CD133+ cell-derived endothelial progenitor cell transplantation. Thromb Haemost 2004;91:1202-12.

7. Asahara T, Takahashi T, Masuda $\mathrm{H}$, et al. VEGF contributes to postnatal neovascularization by mobilizing bone marrow-derived endothelial progenitor cells. EMBO J 1999;18:3964-72.

8. Dimmeler S, Aicher A, Vasa M, et al. HMG-CoA reductase inhibitors (statins) increase endothelial progenitor cells via the PI 3-kinase/Akt pathway. J Clin Invest 2001;108:391-7.

9. Fischer-Rasokat U, Assmus B, Seeger $\mathrm{FH}$, et al. A pilot trial to assess potential effects of selective intracoronary bone marrow-derived progenitor cell infusion in patients with nonischemic dilated cardiomyopathy: final 1-year results of the transplantation of progenitor cells and functional regeneration enhancement pilot trial in patients with nonischemic dilated cardiomyopathy. Circ Heart Fail 2009;2:417-23.

10. Chavakis E, Aicher A, Heeschen C, et al. Role of beta2-integrins for homing and neovascularization capacity of endothelial progenitor cells. J Exp Med 2005;201:63-72.

11. Shintani $\mathrm{S}$, Murohara $\mathrm{T}$, Ikeda $\mathrm{H}$, et al. Mobilization of endothelia progenitor cells in patients with acute myocardial infarction. Circulation 2001;103:2776-9.

12. Werner $\mathrm{N}$, Junk $\mathrm{S}$, Laufs $\mathrm{U}$, et al. Intravenous transfusion of endothelial progenitor cells reduces neointima formation after vascular injury. Circ Res 2003:93:17e-24.

13. Schmidt-Lucke C, Rossig L, Fichtlscherer S, et al. Reduced number of circulating endothelial progenitor cells predicts future cardiovascular events: proof of concept for the clinical importance of endogenous vascular repair. Circulation 2005;111:2981-7.

14. Werner N, Kosiol S, Schiegl T, et al. Circulating endothelial progenitor cells and cardiovascular outcomes. $N$ Engl J Med 2005;353:999-1007.

15. Mills NL, Tura O, Padfield GJ, et al. Dissociation of phenotypic and functional endothelial progenitor cells in patients undergoing percutaneous coronary intervention. Heart 2009;95:2003-8.

16. Padfield GJ, Tura-Ceide O, Freyer E, et al. Endothelial progenito cells, atheroma burden and clinical outcome in patients with coronary artery disease. Heart 2013;99:791-8.

17. Case J, Mead LE, Bessler WK, et al. Human CD34+AC133+VEGFR-2 + cells are not endothelial progenitor cells but distinct, primitive hematopoietic progenitors. Exp Hematol 2007;35:1109-18.

18. Yoder MC, Mead LE, Prater D, et al. Redefining endothelial progenitor cells via clonal analysis and hematopoietic stem/ progenitor cell principals. Blood 2007;109:1801-9.

19. Timmermans F, Van Hauwermeiren F, De Smedt M, et al. Endothelial outgrowth cells are not derived from CD133+ cells or CD45+ hematopoietic precursors. Arterioscler Thromb Vasc Biol 2007;27:1572-9.

20. Rehman J, Li J, Orschell CM, et al. Peripheral blood "Endothelial Progenitor Cells" are derived from monocyte/macrophages and secrete angiogenic growth factors. Circulation 2003;107:1164-9.

21. Fernandez Pujol B, Lucibello FC, Gehling UM, et al. Endothelial-like cells derived from human CD14 positive monocytes. Differentiation 2000;65:287-300.

22. Elsheikh E, Uzunel M, He Z, et al. Only a specific subset of human peripheral blood monocytes has endothelial-like functional capacity. Blood 2005;106:2347-55.

23. Nowak G, Karrar A, Holmén C, et al. Expression of vascular endothelial growth factor receptor-2 or Tie-2 on peripheral blood cells defines functionally competent cell populations capable of reendothelialization. Circulation 2004;110:3699-707.

24. Bruno S, Bussolati B, Scacciatella $P$, et al. Combined administration of G-CSF and GM-CSF stimulates monocyte-derived pro-angiogenic cells in patients with acute myocardial infarction. Cytokine 2006;34:56-65.

25. Ringqvist I, Fisher LD, Mock M, et al. Prognostic value of angiographic indices of coronary artery disease from the Coronary Artery Surgery Study (CASS). J Clin Invest 1983;71:1854-66.

26. Padfield GJ, Tura O, Haeck ML, et al. Circulating endothelial progenitor cells are not affected by acute systemic inflammation. Am J Physiol Heart Circ Physiol 2010;298:H2054-61.

27. Mills NL, Robinson SD, Fokkens PH, et al. Exposure to concentrated ambient particles does not affect vascular function in patients with coronary heart disease. Environ Health Perspect 2008;116:709-15.

28. Pelliccia F, Cianfrocca C, Rosano G, et al. Role of endothelial progenitor cells in restenosis and progression of coronary atherosclerosis after percutaneous coronary intervention: a prospective study. JACC Cardiovasc Interv 2010;3:78-86.

29. Guven H, Shepherd RM, Bach RG, et al. The number of endothelial progenitor cell colonies in the blood is increased in patients with angiographically significant coronary artery disease. J Am Coll Cardiol 2006;48:1579-87. 
30. Fina L, Molgaard HV, Robertson D, et al. Expression of the CD34+ gene in vascular endothelial cells. Blood 1990;75:2417-26.

31. Heissig B, Hattori K, Dias S, et al. Recruitment of stem and progenitor cells from the bone marrow niche requires MMP-9 mediated release of kit-ligand. Cell 2002;109:625-37.

32. Tura O, Skinner EM, Robin Barclay G, et al. Late outgrowth endothelial cells resemble mature endothelial cells and are not derived from bone marrow. Stem Cells 2012;31:338-48.

33. Inoue T, Sata M, Hikichi Y, et al. Mobilization of CD34-positive bone marrow-derived cells after coronary stent implantation: impact on restenosis. Circulation 2007;115:553-61.

34. Schober A, Hoffmann R, Opree N, et al. Peripheral CD34+ cells and the risk of in-stent restenosis in patients with coronary heart disease. Am J Cardiol 2005;96:1116-22.

35. Sata M, Saiura A, Kunisato A, et al. Hematopoietic stem cells differentiate into vascular cells that participate in the pathogenesis of atherosclerosis. Nat Med 2002;8:403-9.

36. Simper D, Stalboerger PG, Panetta CJ, et al. Smooth muscle progenitor cells in human blood. Circulation 2002;106:1199-204.

37. Skowasch D, Jabs A, Andrie R, et al. Presence of bone-marrowand neural-crest-derived cells in intimal hyperplasia at the time of clinical in-stent restenosis. Cardiovasc Res 2003;60:684-91.

38. Urbich C, Heeschen C, Aicher A, et al. Relevance of monocytic features for neovascularization capacity of circulating endothelial progenitor cells. Circulation 2003;108:2511-16.

39. Zhao Y, Glesne D, Huberman E. A human peripheral blood monocyte-derived subset acts as pluripotent stem cells. Proc Nat Acad Sci USA 2003;100:2426-31.
40. Ito WD, Arras M, Winkler B, et al. Monocyte chemotactic protein-1 increases collateral and peripheral conductance after femoral artery occlusion. Circ Res 1997;80:829-37.

41. Fukuda D, Enomoto S, Shirakawa I, et al. Fluvastatin accelerates re-endothelialization impaired by local sirolimus treatment. Eur $J$ Pharmacol 2009;612:87-92.

42. Cipollone F, Marini M, Fazia M, et al. Elevated circulating levels of monocyte chemoattractant protein-1 in patients with restenosis after coronary angioplasty. Arterioscler Thromb Vasc Biol 2001;21:327-34.

43. Hokimoto $\mathrm{S}$, Oike $\mathrm{Y}$, Saito $\mathrm{T}$, et al. Increased expression of monocyte chemoattractant protein-1 in atherectomy specimens from patients with restenosis after percutaneous transluminal coronary angioplasty. Circ J 2002;66:114-16.

44. Furukawa $\mathrm{Y}$, Matsumori $\mathrm{A}$, Ohashi $\mathrm{N}$, et al. Anti-monocyte chemoattractant protein-1/monocyte chemotactic and activating factor antibody inhibits neointimal hyperplasia in injured rat carotid arteries. Circ Res 1999;84:306-14.

45. Aicher A, Zeiher AM, Dimmeler S. Mobilizing endothelial progenitor cells. Hypertension 2005;45:321-5.

46. Thomas $\mathrm{H}$, Avery P, Ahmed J, et al. Local vessel injury following $\mathrm{PCl}$ does not promote early mobilisation of endothelial progenitor cells in the absence of myocardial necrosis. Heart 2008;95:555-8.

47. Sevilla J, Gonzalez-Vicent M, Fernandez-Plaza S, et al. Heparin based anticoagulation during peripheral blood stem cell collection may increase the CD34+ cell yield. Haematologica 2004:89:249-51. 